Burn-up calculation

of different thorium-based fuel matrixes

Zohreh Gholamzadeh,

Seyed Amir Hossein Feghhi, Leila Soltani, in a thermal research reactor Marzieh Rezazadeh, Claudio Tenreiro, using MCNPX 2.6 code Mahdi Joharifard

\begin{abstract}
Decrease of the economically accessible uranium resources and the inherent proliferation resistance of thorium fuel motivate its application in nuclear power systems. Estimation of the nuclear reactor's neutronic parameters during different operational situations is of key importance for the safe operation of nuclear reactors. In the present research, thorium oxide fuel burn-up calculations for a demonstrative model of a heavy water-cooled reactor have been performed using MCNPX 2.6 code. Neutronic parameters for three different thorium fuel matrices loaded separately in the modelled thermal core have been investigated. ${ }^{233} \mathrm{U},{ }^{235} \mathrm{U}$ and ${ }^{239} \mathrm{Pu}$ isotopes have been used as fissile element in the thorium oxide fuel, separately. Burn-up of three different fuels has been calculated at $1 \mathrm{MW}$ constant power. ${ }^{135} \mathrm{X}$ and ${ }^{149} \mathrm{Sm}$ concentration variations have been studied in the modelled core during 165 days burn-up. Burn-up of thorium oxide enriched with ${ }^{233} \mathrm{U}$ resulted in the least ${ }^{149} \mathrm{Sm}$ and ${ }^{135} \mathrm{Xe}$ productions and net fissile production of ${ }^{233} \mathrm{U}$ after 165 days. The negative fuel, coolant and void reactivity of the used fuel assures safe operation of the modelled thermal core containing $\left({ }^{233} \mathrm{U}-\mathrm{Th}\right) \mathrm{O}_{2}$ matrix. Furthermore, utilisation of thorium breeder fuel demonstrates several advantages, such as good neutronic economy, ${ }^{233} \mathrm{U}$ production and less production of long-lived $\alpha$ emitter high radiotoxic wastes in biological internal exposure point of view.
\end{abstract}

Key words: $\mathrm{ThO}_{2} \bullet$ neutronic parameters $\bullet$ fuel burn-up $\bullet{ }^{233} \mathrm{U} \bullet{ }^{235} \mathrm{U} \bullet{ }^{239} \mathrm{Pu}$ fissile material

\section{Z. Gholamzadeh ${ }^{凶}$}

Faculty of Engineering, Univesidad de Talca, 2 Norte 685 Talca, Chile,

Tel.: +56071201702,

E-mail: Cadmium_109@yahoo.com

\section{S. A. H. Feghhi}

Department of Radiation Application,

Shahid Beheshti University,

G. C., Tehran, Iran

L. Soltani, M. Rezazadeh

Nuclear Science \& Technology Research Institute,

Atomic Energy Organization of Iran (AEOI),

G. C., Tehran, Iran

C. Tenreiro

Faculty of Engineering, Univesidad de Talca,

2 Norte 685 Talca, Chile and

Department of Energy Science,

Sungkyunkwan University,

300 Cheoncheon-dong, Suwon, Korea

\section{Joharifard}

Department of Physics,

Firoozkooh Branch, Islamic Azad University,

Firoozkooh, Iran

Received: 27 August 2013

Accepted: 8 August 2014

\section{Introduction}

Thorium is three times more abundant in nature than uranium and occurs mainly as fertile ${ }^{232} \mathrm{Th}$ isotope. From the beginning of a nuclear power programme, the immense potential of ${ }^{232} \mathrm{Th}$ for breeding fissile isotope ${ }^{233} \mathrm{U}$ efficiently in a thermal neutron reactor has been recognised. Several experimental and prototype power reactors successfully operated during the mid-1950s to the mid-1970s using (Th, $\mathrm{U}) \mathrm{O}_{2}$ and (Th, U) $\mathrm{C}_{2}$ fuels in high temperature gas-cooled reactors (HTGRs), (Th, $\mathrm{U}) \mathrm{O}_{2}$ fuel in light water reactors (LWRs) and $\mathrm{LiF} / \mathrm{BeF}_{2} / \mathrm{ThF}_{4} / \mathrm{UF}_{4}$ fuel in molten-salt breeder reactor (MSBR) [1].

Renewed interests in thorium-based fuels have arisen lately based on the need for proliferation resistance, longer fuel cycles, higher burn-up and improved waste form characteristics [2]. Hence, many designs and research have been planned to investigate thorium-based fuel potential in fast and thermal reactors. Weaver and Herring [2] presented calculational results and a comparison of the potential burn-up of a thorium-based and uranium-based mixed oxide fuel in a LWR. They used MOCUP and ORIGEN codes to model a $17 \times 17$ PWR lattice of thorium and uranium MOX fuels with $4 \%$ plutonium. According to their results, the uranium-based 
Table 1. The used materials in the modelled reactor core

\begin{tabular}{lccc}
\hline \multicolumn{1}{c}{ Material } & $\begin{array}{c}\text { Compounds } \\
{[\mathrm{wt} \%]}\end{array}$ & $\begin{array}{c}\text { Density } \\
{\left[\mathrm{g} / \mathrm{cm}^{3}\right]}\end{array}$ & $\begin{array}{c}\text { Thickness } \\
{[\mathrm{cm}]}\end{array}$ \\
\hline Fuel 1 & ${ }^{233} \mathrm{U}: 4,{ }^{232} \mathrm{Th}: 96$ & 11.61 & 1.10 \\
Fuel 2 & ${ }^{235} \mathrm{U}: 4,{ }^{232} \mathrm{Th}: 96$ & 11.61 & 1.10 \\
Fuel 3 & ${ }^{239} \mathrm{Pu}: 4,{ }^{232} \mathrm{Th}: 96$ & 11.64 & 1.10 \\
Cover of fuel & Zircaloy-4 (Sn: $1.4, \mathrm{Fe}: 0.23, \mathrm{Cr}: 0.1, \mathrm{Zr}: 98.27)$ & 6.50 & 0.04 \\
Gap & He & 0.000411 & 0.05 \\
Cover plate & SS-304 (Fe: 69.5, Cr: $19.0, \mathrm{Ni}: 9.5, \mathrm{Mn}: 2.0)$ & 7.92 & 0.20 \\
Reflector & Be: 36, O: 64 & 3.00 & 2.00 \\
\hline
\end{tabular}

fuels outperformed the thorium-based fuels by 1.3-4.6 times for reactivity limitations. However, the plutonium destruction rate per $\mathrm{MWd}-\mathrm{cm}^{3}$ is much higher in the thorium-based fuels, 3.5 times better in the reactor grade plutonium case and 2.7 times better in the weapons grade plutonium case [2].

Lung et al. [3] have reported thorium application histories. As, it is mentioned in the report in 1958 , about $55 \mathrm{~kg}$ of ${ }^{233} \mathrm{U}$ was available in the USA. Whereas, many reactor prototypes were built and operated using $1500 \mathrm{~kg}$ of ${ }^{233} \mathrm{U}$ which was separated in the USA from $900 \mathrm{t}$ of thorium. Also another point was mentioned in that report, thorium oxide, uranium oxide and plutonium oxide have similar physical characteristics so that these fuels meet identical condition in different physical limitations of a nuclear reactor, for instance fuel stability by temperature enhancement and so on [3]. India is continuing with its heavy water reactor programme using some thorium fuel elements to flatten the flux in the core [3]. One of the thorium-based reactor projects in India is KAMINI which is a ${ }^{233} \mathrm{U}$ fuelled tank type, beryllium oxide reflected, light water cooled low power research reactor. This reactor is designed to operate at a nominal power of $30 \mathrm{~kW}$ and uses a low fuel production of $590 \mathrm{~g}$ of ${ }^{233} \mathrm{U}$ in the form of uranium-aluminium alloy plates [4]. Another Indian thorium-based reactor is AHWR which is a $300 \mathrm{MWe} / 920 \mathrm{MWh}$, vertical pressure tube type thorium-based reactor cooled by boiling light water and moderated by heavy water. In this design, different matrixes of thorium-based fuel have been used in inner and outer rings of every fuel cluster [5].

Since the early 1990s, Russia had a programme based at Moscow's Kurchatov Institute to develop a thorium-uranium fuel cycle. They used a blanket consisting of uranium-thorium oxide fuel pellets (ratio of uranium to thorium was 1:9, with the uranium enriched up to almost 20\%) in 228 cladding tubes of zirconium alloy, 8.4-mm diameter. These pellets were in four layers around the centre portion. The blanket material achieved 100 GWd burn-up. Together as one fuel assembly, the seed and blanket have the same geometry as a normal VVER-100 fuel assembly [6].

In general, depending on the behaviour of the nuclear fuels and the nuclear design a thermal breeder reactor is commercially feasible only with thorium fuel which avoids the buildup of the heavier transuranics $[7,8]$. The high temperature thorium-fuelled reactor is a special type of the gas-cooled reactor, only one of these types has operated so far, between 1985 and 1989 in Germany. The thermal power of the thorium-based reactor was $760 \mathrm{MW}$, while the electrical power was $307 \mathrm{MW}$ with an efficiency of $40.5 \%$. Th- $U$ balls have been used in reactor vessel with composition of $1 \mathrm{~g}{ }^{235} \mathrm{U}$ and $10 \mathrm{~g}$ ${ }^{232} \mathrm{Th}$ in any ball [9].

In this work MCNPX is used to calculate steady-state reaction rates and normalisation parameters while CINDER90 is used to calculate the time-dependent isotope buildup/depletion $[10,11]$.

\section{Reactor specification and method}

A demonstrative example of a thermal core with hexagonally-arranged 37-assemblies has been modelled using MCNPX 2.6 code. Heavy water has been used as coolant and moderator for the modelled reactor. A 3D neutronic model was set up using MCNPX 2.6 code in cold zero power conditions by means of ENDF/B-VI continuous-energy cross section. The fuel and heavy water temperature was assumed to be $20^{\circ} \mathrm{C}$. The cross sections $\mathrm{S}(\alpha, \beta)$ have been used for $\mathrm{BeO}$ reflector material and heavy water. KCODE with 15000 initial neutrons, 250 effective cycles and 50 ineffective cycles has been used for neutronic parameter calculations. The 37 -assembly core of $35-\mathrm{cm}$ radius and $70-\mathrm{cm}$ height has been modelled according to the dimensions and materials mentioned in Table 1. The fuel assemblies have 19 fuel rods of $50-\mathrm{cm}$ height, 0.5-mm helium gap and 0.4-mm zirconium alloy cover which have been placed in pitch to diameter (P/D) ratio of 1.39 in any assembly.

Cross sectional view of the modelled core has been presented in Fig. 1. As it is obvious in Fig. 1, fuel rods have been placed in hexagonal array and 19 rods have been used in any assembly. One fuel rod has been removed from six central assemblies to allow control rods to be loaded.

Some dynamic parameters $\left(\beta, \beta_{e f f}, \Lambda\right.$ and $\left.\rho\right)$ of the thermal modelled core have been calculated for the different thorium fuel matrix loads in the core separately. Delayed neutron fraction and effective delayed neutron fraction have been calculated for the different fuel matrixes. Reactivity $\left\{\rho=\left[\left(k_{e f f}-1\right)\right.\right.$ $\left.\left./ k_{e f f}\right]\right\}$ of a reactor core is an important parameter, which is given in pcm unit or a unit of $\rho / \beta_{\text {eff }}$ called a 'dollar' [11]. Here $\beta_{e f f}$ is the effective delayed neutron fraction defined as the number of fissions induced by delayed neutrons $\left(N_{d}\right)$ compared to the total number of fissions induced in the same system $\left(N_{t o t}\right)$ [12]. 


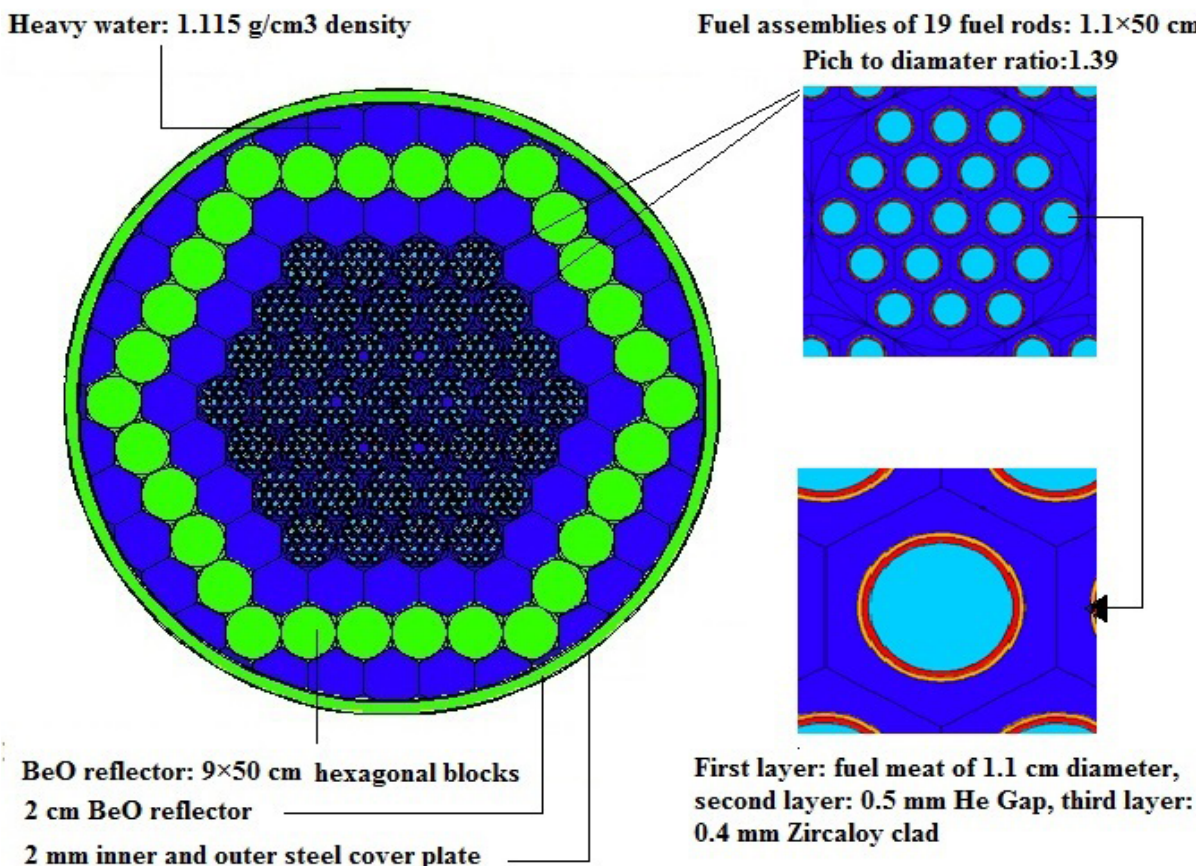

Fig. 1. Schematic cross-sectional view of the modelled core.

$$
\beta_{\text {eff }}=\frac{N_{d}}{N_{t o t}}
$$

The parameter calculation using MCNPX 2.6 code can be carried out by using TOTNU and PHYS card. Delayed neutron fraction, $\beta$, is obtained using $\beta=$ $1-K_{3} / K_{2}$, formula where $K_{2}$ is multiplication factor on prompt and delayed neutrons and $K_{3}$ is only from prompt neutrons. Effective delayed neutron fraction, $\beta_{\text {eff }}$, is obtained using formula $\beta_{\text {eff }}=1-K_{3} / K_{1}$, where $K_{1}$ is multiplication factor on prompt neutrons plus effective contribution of delayed neutrons and $K_{3}$ is from prompt neutrons only [13]. Neutron generation time $(\Lambda)$ of the core has been calculated using the following equation:

$$
\Lambda=\frac{l}{k_{e f f}}
$$

where $l$ is neutron life time and $k_{\text {eff }}$ is effective multiplication of the simulated core [12]. The F4 tally is used to calculate neutron flux and the code outputs could be normalised by multiplication in source particles $[14,15]$. The results of calculations include, among others, the burn-up dependent energy integrated neutron flux, number of neutrons per fission, effective multiplication factor, energy released per fission, isotope mass and activity. Mathematically, the material balance process can be described by depletion equation [16]. The modelled core burn-up calculations have been carried out using identical fuel zones and the burn-up equation was solved for whole core.

Isotopic content was kept as an average for the whole fuel assembly and an average flux level was used in the solution of the burn-up equation in this work. Because this work is a comparative study for neutronic behaviour of the different fissile loads in the modelled core, axial meshing of any fuel pin and radial zoning of the modelled core has been avoided to decrease computation time to some days.

Three burn-up runs have been done for every fuel matrixes, respectively. One MW power has been used for burn-up calculations of (Th $\left.+{ }^{233} \mathrm{U}\right) \mathrm{O}_{2}$, $\left(\mathrm{Th}+{ }^{235} \mathrm{U}\right) \mathrm{O}_{2}$ and $\left(\mathrm{Th}+{ }^{239} \mathrm{Pu}\right) \mathrm{O}_{2}$ fuel matrixes. Void worth value due to coolant density variation has been calculated for the core fed with different thorium-based fuel matrixes using perturbation card of MCNPX 2.6 code. Temperature effects on effective multiplication factor have been investigated using fuel and moderator temperature-related cross sections of 70c, 71c and 72c and TMP card of MCNPX code. Fuel and moderator temperature effects on effective multiplication factor of the core have been studied separately. The power density of the modelled core fed the different fuel matrices has been separately calculated using F6 tally. Actinide production has been compared for the fuel matrixes after 165-day-burn-up.

\section{Results and discussion}

The dynamic parameters of the three investigated cores are given in Table 2, where it is seen that the delayed neutron fraction of plutonium-enriched fuel does not ensure the stability of the system.

As it is obvious from Fig. 2, the core multiplication decreases during first 30 days in cases of both thorium-based fuels enriched with ${ }^{233 / 235} \mathrm{U}$. After 30 days, the effective multiplication of both fuels are approximately constant between 45 and 165 days with maximum changes less than 244 pcm for $\left({ }^{233} \mathrm{U}\right.$ $\left.+{ }^{232} \mathrm{Th}\right) \mathrm{O}_{2}$ and $469 \mathrm{pcm}$ for $\left({ }^{235} \mathrm{U}+{ }^{232} \mathrm{Th}\right) \mathrm{O}_{2}$. In case of $\left({ }^{239} \mathrm{Pu}+{ }^{232} \mathrm{Th}\right) \mathrm{O}_{2}$, the multiplication factor has a descending slope during total burn-up duration.

Neutron flux is almost constant during the 3-month-operation for both the uranium-enriched cores. The flux value of $10^{13} \mathrm{n} / \mathrm{s} \cdot \mathrm{cm}^{2}$ is completely suitable for research purposes. In case of plutonium- 
Table 2. Dynamic parameters of the modelled core with three different fuel loads

\begin{tabular}{lcccc}
\hline \multicolumn{1}{c}{ Fuel type } & $\begin{array}{c}\beta \\
{[\mathrm{pcm}]}\end{array}$ & $\begin{array}{c}\beta_{\text {eff }} \\
{[\mathrm{pcm}]}\end{array}$ & $\begin{array}{c}\Lambda \\
{[\mu \mathrm{s}]}\end{array}$ & $\begin{array}{c}\rho \\
{[\mathrm{pcm}]}\end{array}$ \\
\hline$\left(\mathrm{Th}^{235} \mathrm{U}\right) \mathrm{O}_{2}$ & 635 & 711 & 60.99 & 17163.68 \\
$\left(\mathrm{Th}^{233} \mathrm{U}\right) \mathrm{O}_{2}$ & 252 & 373 & 54.36 & 24797.89 \\
$\left(\mathrm{Th}-{ }^{239} \mathrm{Pu}\right) \mathrm{O}_{2}$ & 285 & 226 & 35.12 & 27029.14 \\
\hline
\end{tabular}

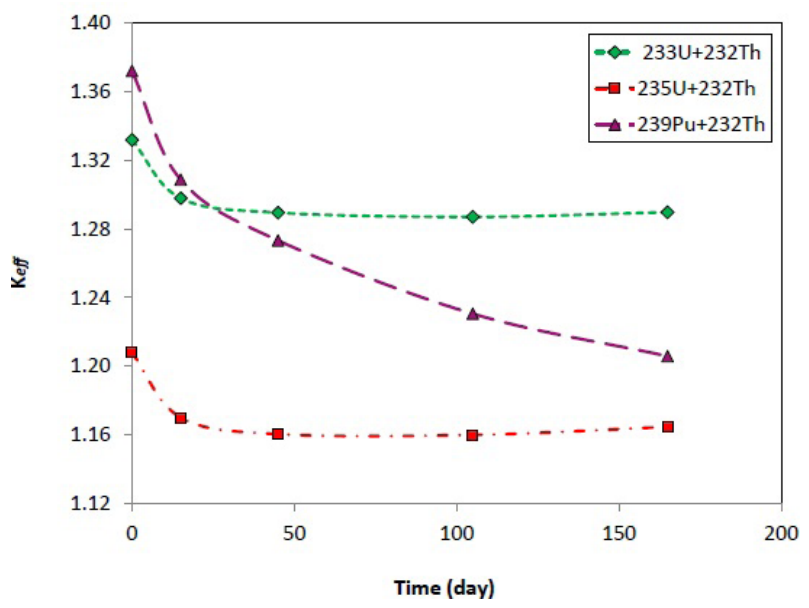

Fig. 2. Dependence of effective multiplication factor on burn-up time.

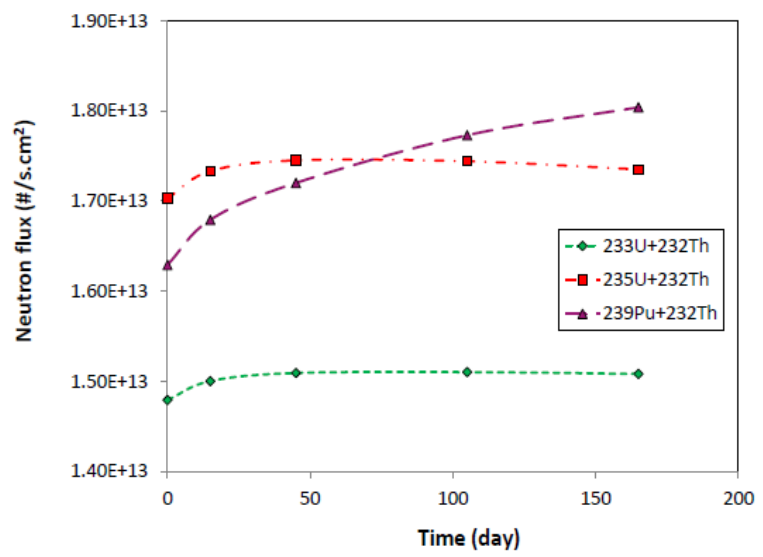

Fig. 3. Dependence of integrated neutron flux over the whole energy range on burn-up.

-enriched fuel, there is an ascending slope for neutron flux during the burn-up process (Fig. 3).

The latter is a consequence of effective multiplication factor reduction during the burn-up process on constant power.

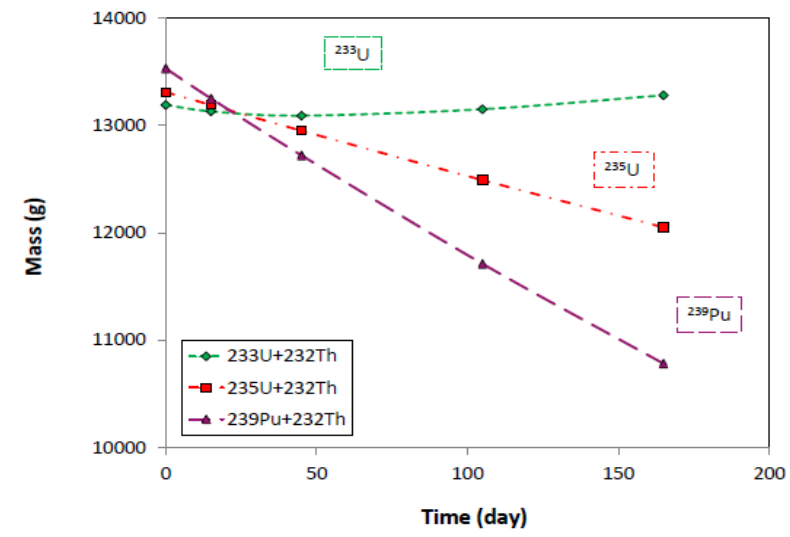

Fig. 4. Fissile mass burn-up for three cores.
Fuel burn-up calculations showed a depletion of $1.26 \mathrm{~kg}$ of ${ }^{235} \mathrm{U}$ during $165 \mathrm{MWd}$ in case of (Th + $\left.{ }^{235} \mathrm{U}\right) \mathrm{O}_{2}$ fuel loaded into the core. In the modelled core with (Th $\left.+{ }^{233} \mathrm{U}\right) \mathrm{O}_{2}$ fuel, $100 \mathrm{~g}$ of ${ }^{233} \mathrm{U}$ depletes in 45 days. The ${ }^{233} \mathrm{U}$ mass starts to grow leading to additional $100 \mathrm{~g}$ at about $110 \mathrm{MWd}$, and thus to the total of $90 \mathrm{~g}$ production of ${ }^{233} \mathrm{U}$. Burn-up of plutonium-enriched core results in $2.75 \mathrm{~kg}{ }^{239} \mathrm{Pu}$ depletion during burn-up process is shown in Fig. 4.

The detailed results show $90 \mathrm{~g}$ of ${ }^{233} \mathrm{U}$ produced during the (Th $\left.+{ }^{233} \mathrm{U}\right) \mathrm{O}_{2}$ fuel burn-up of $165 \mathrm{MWd}$, and $0.64 \mathrm{~g}^{235} \mathrm{U}$ produced during this time. During $\left(\mathrm{Th}+{ }^{235} \mathrm{U}\right) \mathrm{O}_{2} 165 \mathrm{MWd}$ burn-up $1.1 \mathrm{~kg}$ of ${ }^{233} \mathrm{U}$ will be produced. Moreover $1.08 \mathrm{~kg}^{233} \mathrm{U}$ and $0.17 \mathrm{~g} 235 \mathrm{U}$ is produced in the core fed with $\left(\mathrm{Th}+{ }^{239} \mathrm{Pu}\right) \mathrm{O}_{2}$ after 165 MWd (Fig. 5).

As concentration of ${ }^{135} \mathrm{Xe}$ and ${ }^{149} \mathrm{Sm}$ neutron poisons is connected with reactor safety and reactivity fluctuations of a reactor, the determination of these poisons concentration is important for precise estimation of neutronic behaviour of a core during

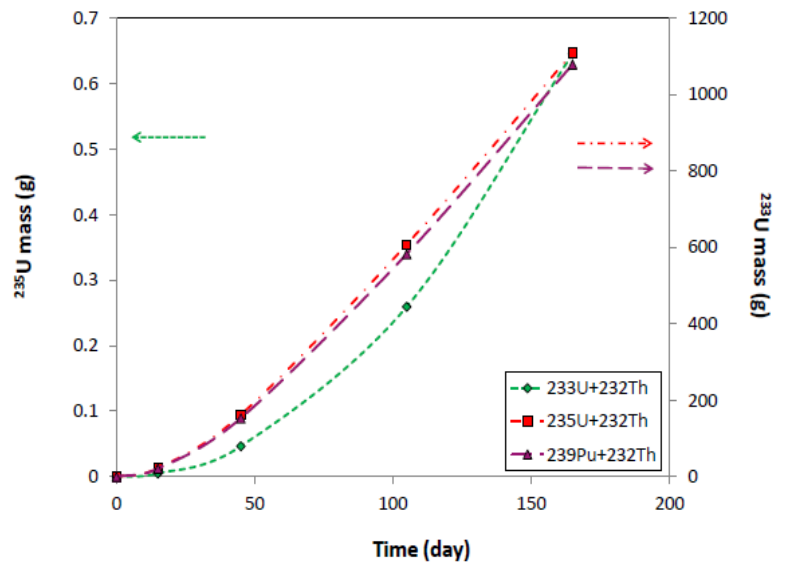

Fig. 5. Dependence of fissile mass production on burn-up time.

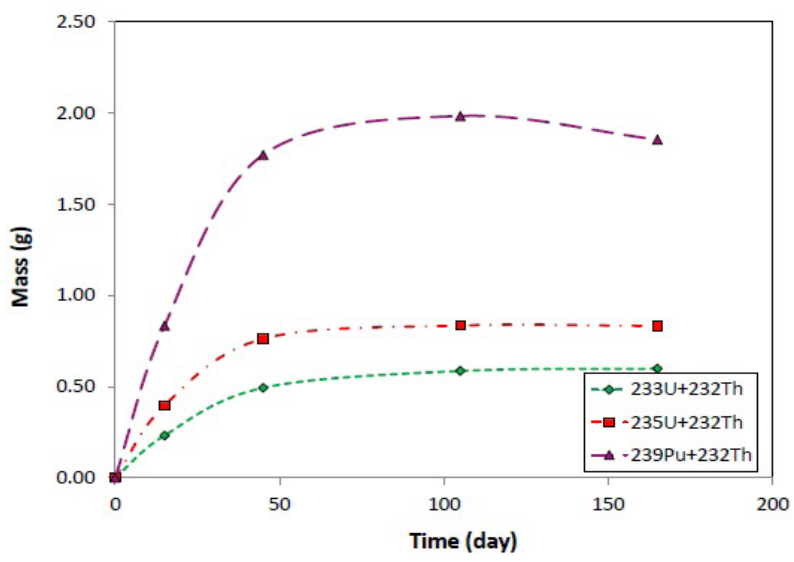

Fig. 6. Dependence of ${ }^{149} \mathrm{Sm}$ concentration on burn-up time. 
its operation as well as its restart after a short shut down time. The concentration of ${ }^{149} \mathrm{Sm}$ is noticeably higher in the core with ${ }^{239} \mathrm{Pu}$ than in other cases. In this core the ${ }^{149} \mathrm{Sm}$ peak is 2.38 and 3.38 times greater than in the cores with ${ }^{235} \mathrm{U}$ and ${ }^{233} \mathrm{U}$, respectively (Fig. 6).

The ${ }^{135} \mathrm{Xe}$ concentration is also higher for the core with ${ }^{239} \mathrm{Pu}$ (Fig. 7).

A mass of $1.2 \mathrm{~kg}$ of ${ }^{232} \mathrm{Th}$ has been consumed during $165 \mathrm{MWd}$ in the core fed with $\left({ }^{233} \mathrm{U}+{ }^{232} \mathrm{Th}\right)$ $\mathrm{O}_{2}, 1.4 \mathrm{~kg}$ after $165 \mathrm{MWd}$ for $\left({ }^{235} \mathrm{U}+{ }^{232} \mathrm{Th}\right) \mathrm{O}_{2}$ and $\left({ }^{239} \mathrm{Pu}+{ }^{232} \mathrm{Th}\right) \mathrm{O}_{2}$ fuels. The ${ }^{237} \mathrm{~Np}$ production is non-detectable in the core fed with $\left.{ }^{233} \mathrm{U}+{ }^{232} \mathrm{Th}\right)$ $\mathrm{O}_{2}$ while there is $\sim 0.2 \mathrm{~g}{ }^{237} \mathrm{~Np}$ after $165 \mathrm{MWd}$ for $\left({ }^{235} \mathrm{U}+{ }^{232} \mathrm{Th}\right) \mathrm{O}_{2}$ fuel. The $\alpha$ emitter radioisotope is non-detectable after $165 \mathrm{MWd}$ for $\left({ }^{239} \mathrm{Pu}+{ }^{232} \mathrm{Th}\right)$ $\mathrm{O}_{2}$ fuel as well. But, there are isotopes ${ }^{238 / 239 / 240 / 241} \mathrm{Pu}$, ${ }^{241} \mathrm{Am}$ and ${ }^{242} \mathrm{Cm}$ which are $\beta$ emitter radioisotopes.

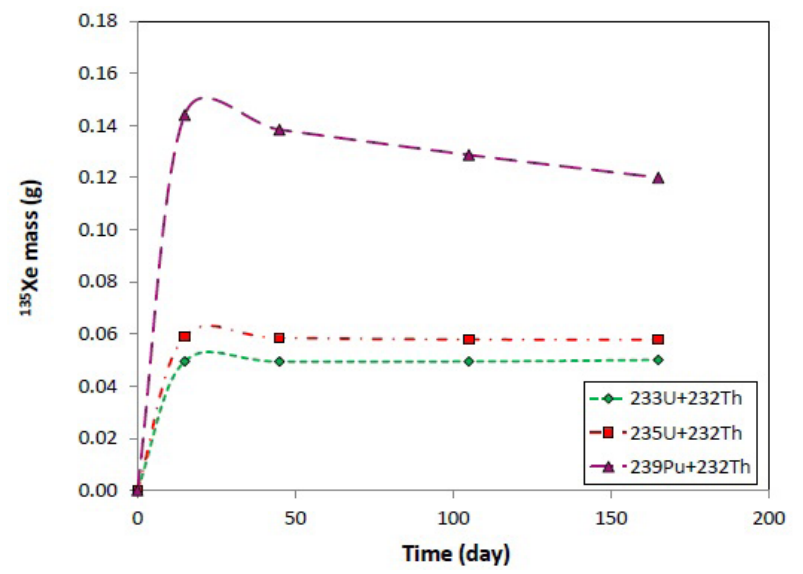

Fig. 7. Dependence of ${ }^{135} \mathrm{Xe}$ concentration on burn-up time.

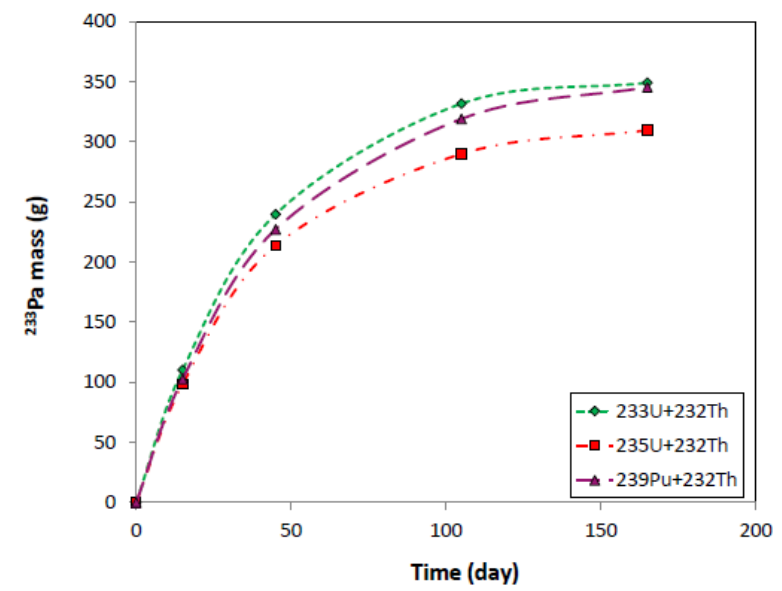

Fig. 8. Dependence of ${ }^{233} \mathrm{~Pa}$ concentration on burn-up time.
${ }^{233} \mathrm{~Pa}$ isotope plays a vital role in reactivity variations of the core due to the fact that its decay chain ends with ${ }^{233} \mathrm{U}$ fissile material after 27 days. As Fig. 8 shows, ${ }^{233} \mathrm{~Pa}$ concentration is about $39.5 \mathrm{~g}$ higher in $\left({ }^{233} \mathrm{U}+{ }^{232} \mathrm{Th}\right) \mathrm{O}_{2}$ fuel matrix than in $\left({ }^{235} \mathrm{U}+{ }^{232} \mathrm{Th}\right)$ $\mathrm{O}_{2}$ one. The production of ${ }^{233} \mathrm{~Pa}$ is approximately identical for both ${ }^{233} \mathrm{U}$ and ${ }^{239} \mathrm{Pu}$ enriched fuels.

The obtained amounts of isotopes after $165 \mathrm{MWd}$ have been presented in Table 3 .

Gas and bubble production increases through the core coolant process with decreasing density. Such phenomenon usually is called 'void formation' inside the core coolant. As it is obvious in Fig. 9, void worth variations caused by coolant density variations are less pronounced for the core with ${ }^{235} \mathrm{U}$ while its changes are faster and negative in case of ${ }^{233} \mathrm{U}$ enriched core. The value may be increasing with void percentage for ${ }^{239} \mathrm{Pu}$ enriched core, based on the fact that void formation shifts the neutron spectra from thermal to fast and increases the fission rate.

As Fig. 10 shows, fuel temperature reactivity coefficients are negative for the investigated fuel matrixes. Among them, the most negative temperature reactivity coefficient belongs to ${ }^{235} \mathrm{U}$ enriched core, in which reactivity changes - by around $2055 \mathrm{pcm}$ during transition from 293 to $599 \mathrm{~K}$. The respective changes for ${ }^{233} \mathrm{U}$ and ${ }^{239} \mathrm{Pu}$ enriched cores are 1270 and $886 \mathrm{pcm}$, respectively.

In calculation of the effect of the heavy water temperature the change in its density had to be taken into account [17]. The results are presented in Fig. 11. The ${ }^{239} \mathrm{Pu}$ enriched core encounters the effective multiplication factor growth of about $1064 \mathrm{pcm}$ with coolant temperature increase to $898 \mathrm{~K}$. In the ${ }^{235} \mathrm{U}$ enriched core the same change of temperature causes a

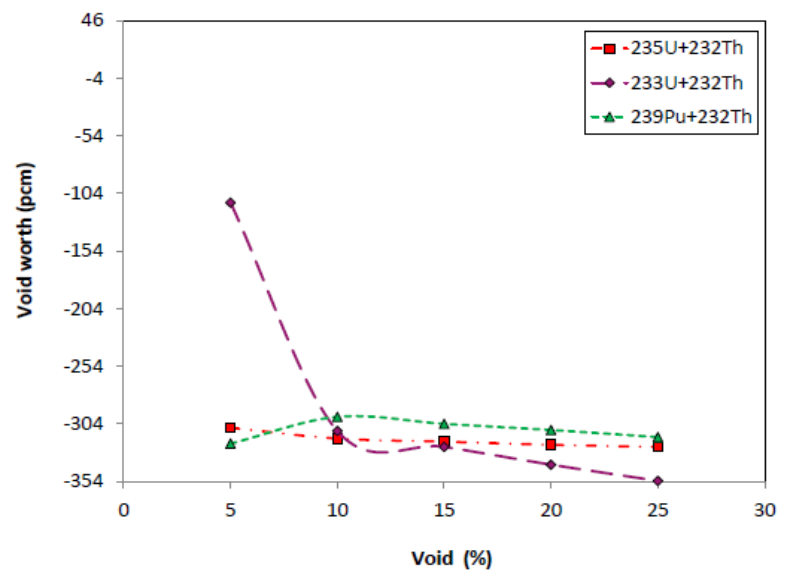

Fig. 9. Comparison of void worth of the core fed with different fuel matrixes.

Table 3. Comparison of the amounts of basic isotopes after $165 \mathrm{MWd}$ for three different fuel loads

\begin{tabular}{cccccccc}
\hline $\begin{array}{c}\text { Fuel } \\
\text { type }\end{array}$ & $\begin{array}{c}\text { Th } \\
\text { consumption } \\
{[\mathrm{g}]}\end{array}$ & $\begin{array}{c}\text { Fissile } \\
\text { consumption } \\
{[\mathrm{g}]}\end{array}$ & $\begin{array}{c}{ }^{233} \mathrm{U} \\
\text { production } \\
{[\mathrm{g}]}\end{array}$ & $\begin{array}{c}{ }^{235} \mathrm{U} \\
\text { production } \\
{[\mathrm{g}]}\end{array}$ & $\begin{array}{c}{ }^{135} \mathrm{Xe} \\
\text { production } \\
{[\mathrm{g}]}\end{array}$ & $\begin{array}{c}{ }^{149} \mathrm{Sm} \\
\text { production } \\
{[\mathrm{g}]}\end{array}$ & $\begin{array}{c}{ }^{233} \mathrm{~Pa} \\
\text { production } \\
{[\mathrm{g}]}\end{array}$ \\
\hline$\left(\mathrm{Th}^{-235} \mathrm{U}_{2} \mathrm{O}_{2}\right.$ & 1400 & 1260 & 1100 & 0.64 & 0.0057 & 0.832 & 309.4 \\
$\left(\mathrm{Th}-{ }^{233} \mathrm{U}\right) \mathrm{O}_{2}$ & 1200 & $*$ & 90 & ND & 0.0050 & 0.598 & 348.2 \\
$\left(\mathrm{Th}-{ }^{239} \mathrm{Pu}\right) \mathrm{O}_{2}$ & 1400 & 2750 & 1080 & 0.17 & 0.1200 & 1.850 & 345.2 \\
\hline
\end{tabular}

*In case of this fuel, production and consumption of ${ }^{233} \mathrm{U}$ is simultaneously occurring so its net production after 165 days has been reported in the table. ND - non-detectable. 


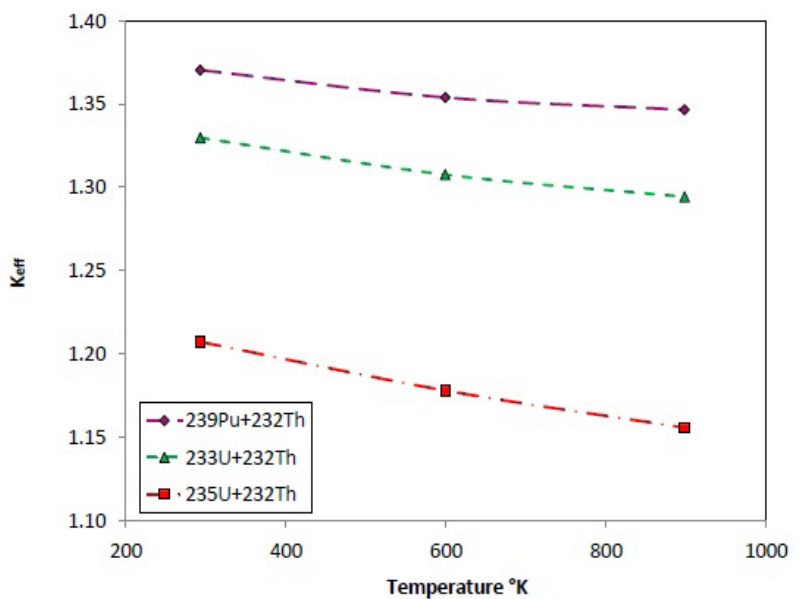

Fig. 10. Comparison of fuel temperature effects on multiplication factor of the core fed with different fuel matrixes.

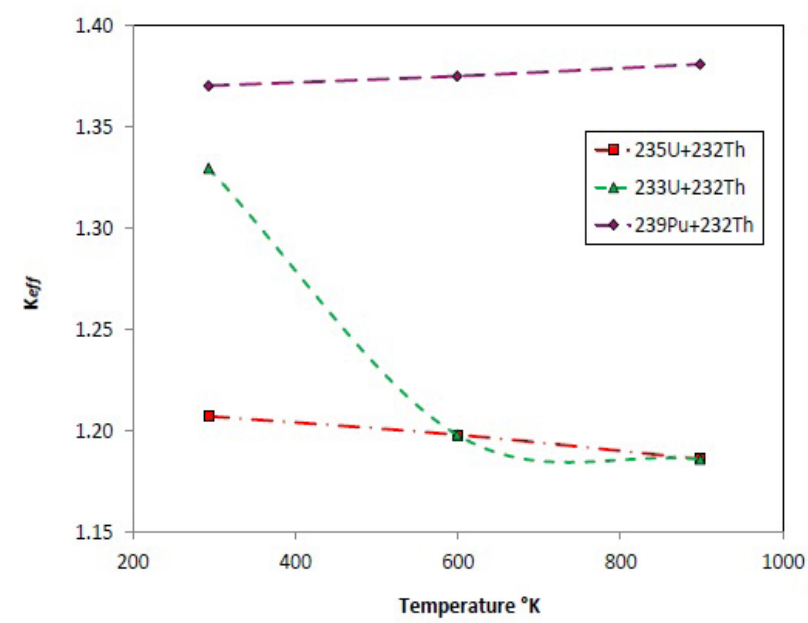

Fig. 11. Comparison of moderator temperature effects on multiplication factor of the core fed with different fuel matrixes.

$2120 \mathrm{pcm}$ decrease of the effective multiplication factor. In case of ${ }^{233} \mathrm{U}$ enriched core the effective multiplication factor decrease is still more pronounced as it reaches $14375 \mathrm{pcm}$.

Although, a positive temperature reactivity coefficient will be obtained as a result of heavy water density reduction in higher temperatures in case of $\left({ }^{239} \mathrm{Pu}-\mathrm{Th}\right) \mathrm{O}_{2}$ loaded core, but noticeably higher negative fuel temperature reactivity coefficient can guarantee the core safety during its operation. Investigation of radial power density showed the highest power density is $37.8 \mathrm{~W} / \mathrm{cm}^{3}$ for the ${ }^{239} \mathrm{Pu}$ enriched core. The value is 35.5 and $33.6 \mathrm{~W} / \mathrm{cm}^{3}$ for ${ }^{233} \mathrm{U}$ and ${ }^{235} \mathrm{U}$ enriched cores, respectively (Fig. 12).

To summarise, the higher absolute values of reactivity coefficients belong to the ${ }^{233} \mathrm{U}$ enriched core

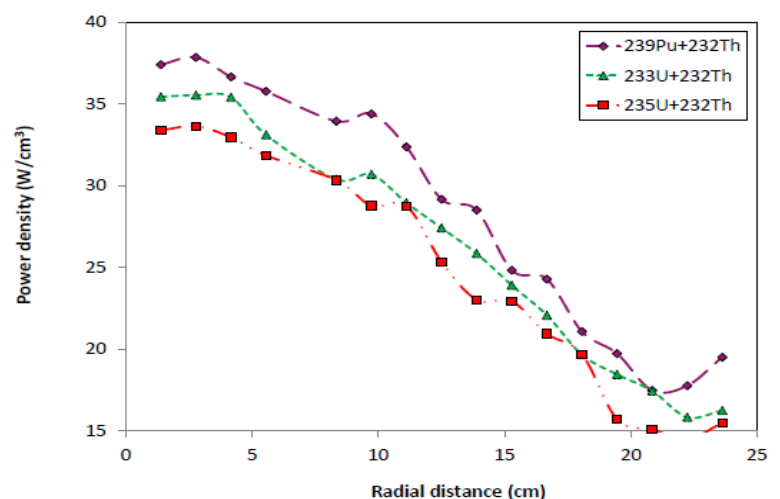

Fig. 12. Comparison of radial power density of the core fed with different fuel matrixes.

and the least values belong to the ${ }^{239} \mathrm{Pu}$ enriched core (Table 4).

As shown in Table 5, total activity of $\alpha$ emitter actinides at end of $165 \mathrm{MWd}$ is higher in case of ${ }^{239} \mathrm{Pu}$ enriched core $(856 \mathrm{Ci})$ than ${ }^{233} \mathrm{U}$ and ${ }^{235} \mathrm{U}$ enriched cores (129 Ci and $10.8 \mathrm{Ci}$, respectively).

In general, the thorium-based fuel matrixes are more favourable from the point of view of long half-life $\alpha$ emitter proliferation as well as high breeding ability, what explains the efforts towards the replacement by them of uranium-based fuel matrixes. Thorium dioxide is the most stable oxide form of thorium, which may further improve the spent fuel repository performance. The fuel cost and the amount of spent fuel per unit energy generation can be reduced due to proliferation resistance of thorium-based fuel and its breeding capability in both thermal and fast neutron flux [18]. However, there are some disadvantages for the thorium fuel. From a neutronic point of view, the epithermal resonance absorption in ${ }^{232} \mathrm{Th}$ is lower than that in ${ }^{238} \mathrm{U}$ which can result in less negative resonance reactivity feedbacks. ${ }^{233} U$ has a smaller delayed neutron fraction $(\beta)$ than that of ${ }^{235} U$ but comparable to that of ${ }^{239} \mathrm{Pu}$, thus creating a need for faster response of control systems to transients, when ${ }^{235} \mathrm{U}$ is not present in sufficient amount. Finally, positive reactivity of the thorium-fueled core due to ${ }^{233} \mathrm{~Pa}$ decay after shut down should be seriously analysed for such fuel matrix [18].

\section{Conclusion}

${ }^{233} \mathrm{U}$ is a long-lived fissile isotope produced in reactors by single-neutron capture in fertile isotope of ${ }^{232} \mathrm{Th}$. Main reason of interest in the fertile isotopes as a reactor fuel is their achievable superior conversion ratios (CR) in thermal reactors. The results

Table 4. Comparison of reactivity effect for $165 \mathrm{MWd}$ burn-up and maximum power density of the modelled core fed with the different fuel matrix

\begin{tabular}{lccc}
\hline \multicolumn{1}{c}{ Fuel type } & $\left(\mathrm{Th}^{235}{ }^{23}\right) \mathrm{O}_{2}$ & $\left(\mathrm{Th}-{ }^{233} \mathrm{U}\right) \mathrm{O}_{2}$ & $\left(\mathrm{Th}^{239} \mathrm{Pu}\right) \mathrm{O}_{2}$ \\
\hline Power density [W/cm $\left.{ }^{3}\right]$ & 33.6 & 35.5 & 37.8 \\
Void reactivity effect: $\Delta k / k[\%]$ & -1.574 & -1.431 & -1.538 \\
Fuel temperature reactivity effect: $\Delta k / k[\%]$ & -4.271 & -2.663 & -1.739 \\
Coolant temperature reactivity effect: $\Delta k / k[\%]$ & -1.756 & -10.801 & 0.776 \\
Total reactivity effect: $\Delta k / k[\%]$ & -7.601 & -14.905 & -2.501 \\
\hline
\end{tabular}




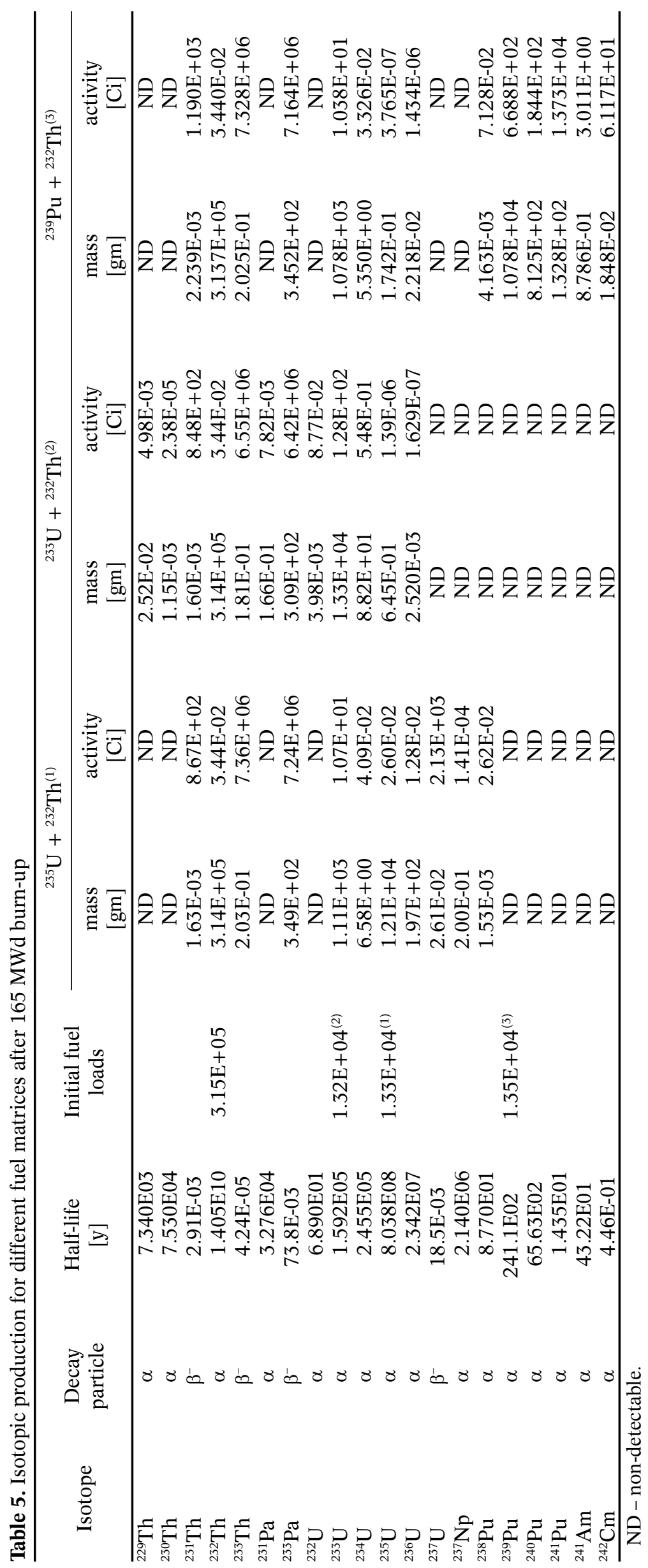


obtained in this work showed that the ${ }^{233} \mathrm{U}$-enriched thorium oxide fuel leads to the lowest ${ }^{135} \mathrm{Xe}$ and ${ }^{149} \mathrm{Sm}$ reactivity in the investigated model of the thermal reactor. The same fuel also has the most negative void worth. Fuel temperature reactivity coefficients of the ${ }^{233} \mathrm{U}$-enriched thorium oxide fuel were less negative than those of ${ }^{235} \mathrm{U}$-enriched fuel. In general, ${ }^{233 / 235} \mathrm{U}$-enriched thorium oxide fuels meet more acceptable safety margins than ${ }^{239} \mathrm{Pu}$-enriched thorium oxide fuel with the lowest delayed neutron fractions and less negative temperature reactivity coefficients. In the investigated model, $2.75 \mathrm{~kg}$ of ${ }^{239} \mathrm{Pu}$ has been depleted but its noticeable $\alpha$ emitter impurity production $(856 \mathrm{Ci}$ ) and its poor neutron generation time (35.12 $\mu \mathrm{s})$ represent disadvantages of the Pu-enriched thorium fuel. ${ }^{239} \mathrm{Pu}$ incineration in proposed systems suggests that ${ }^{235} \mathrm{U}$ in thorium-based fuel matrix could ensure safer operation of the thermal reactor. Highly desirable breeding ability of thorium-based fuel matrixes as well as their proliferation resistance to long half-life $\alpha$ emitter isotopes makes them economical and biological friendly options for contemporary power and research reactors.

\section{References}

1. IAEA. (2005). Thorium fuel cycle-potential benefits and challenges. Vienna: International Atomic Energy Agency. (IAEA-TECDOC-1450).

2. Weaver, K. D., \& Herring, J. S. (2002). Performance of thorium-based mixed oxide fuels for the consumption of plutonium in current and advanced reactors. In International Congress on Advanced Nuclear Power Plants (ICAPP). ANS Annual Meeting, 9-13 June 2002, Hollywood, Florida, USA.

3. Lung, M., \& Gremm, O. (1998). Perspectives of the thorium fuel cycle. Nucl. Eng. Des., 180, 133-146.

4. Usha, S., Ramanarayanan, R. R., Mohanakrishnan, P., \& Kapoor, R. P. (2006). Research reactor KAMINI. Nucl. Eng. Des., 236, 872-880.

5. Kumar, A., Srivenkatesan, R., \& Sinha, R. K. (2009). On the physics design of advanced heavy water reactor (AHWR). In International Conference on Opportunities and Challengers for Water Cooled Reactors in the 21st Century, 27-28 October 2009 (pp. 84-85). Vienna: International Atomic Energy Agency. (IAEA-CN-164).

6. Maitra, R. (2005) Thorium: Preferred nuclear fuel of the fuel. Sci. Technol., 18, 64-71.
7. Sasidharan, K., \& Chafale, S. B. (2012). New reactor concepts. BARC Highlights - Reactor Technology and Engineering, from http://barc.gov.in/publications/eb/ golden/reactor/toc/chapter9/9.pdf.

8. Pelowitz, D. B. (2008). MCNPX2.6.0 user manual. Los Alamos: Los Alamos National Laboratory (LA-CP-07-1473).

9. Thorium high temperature reactor (THTR), from paksnuclearpowerplant.com.

10. Fensin, M. L. (2008). Development of the MCNPX depletion capability: A Monte Carlo depletion method that automates the coupling between MCNPX and CINDER90 for high fidelity burn-up calculations. Doctoral dissertation, University of Florida.

11. Persson, C. -M. (2005). Reactivity determination and Monte Carlo simulation of the subcritical reactor experiment - "Yalina". Master of Science Thesis, Department of Nuclear and Reactor, Physics Royal Institute of Technology, Stockholm, from http://neutron.kth.se/publications/library/CalleMSc.pdf.

12. Hassanzadeh, M., Feghhi, S. A. H., \& Khalafi, H. (2013). Calculation of kinetic parameters in an accelerator driven subcritical TRIGA reactor using MCNIC method. Ann. Nucl. Energy, 59, 188-193.

13. Westlen, D. (2007). Why faster is better - on minor actinide transmutation in hard neutron spectra. Doctoral dissertation, Division of Reactor Physics, University of Stockholm, from http://neutron.kth. se/publications/PhDtheses.shtml

14. Snoj, L., \& Ravnik, M. (2006). Calculation of power density with MCNP in TRIGA reactor. In Proceedings of the International Conference on Nuclear Energy for New Europe, 12-15 September 2006 (Paper no. 109, pp. 1-6). Portoroz, Slovenia.

15. Shultis, J. K., \& Faw, R. E. (2011) An MCNP primer. Department of Mechanical and Nuclear Engineering, Kansas State University, from http://krex.ksu.edu.

16. El Bakkari, B., El Bardouni, T., Merroun, O., El Younoussi, Ch., Boulaich, Y., \& Chakir, E. (2009). Development of an MCNP-tally based burn-up code and validation through PWR benchmark exercises. Ann. Nucl. Energy, 36, 626-633.

17. Marin, T. W., Takahashi, K., \& Bartels, D. M. (2006). Temperature and density dependence light and heavy water ultraviolet absorption edge. Chem. Phys., 125, $1-11$.

18. Kazimi, M. S., Czerwinski, K. R., Driscoll, M. J., Hejzlar, P., \& Meyer, J. E. (1999). On the use of thorium in light water reactors. Department of Nuclear Engineering, Massachusetts Institute of Technology. (MIT-NFC-TR-016), from http://www.ltbridge.com/ assets/15.pdf. 